\title{
Geophysical characterization of a Proterozoic REE terrane at Mountain Pass, eastern Mojave Desert, California
}

\author{
K.M. Denton, D.A. Ponce, J.R. Peacock, and D.M. Miller ${ }^{1}$ \\ ${ }^{1}$ U.S. Geological Survey, Menlo Park, CA
}

\section{\&RQMQWRIIWNV $\dot{c}$ (OH}

\section{Text S1}

2. Figures $\mathrm{S} 1$ to $\mathrm{S} 20$

\section{Introduction}

This supplementary material contains information related to two-dimensional (2-D) modeling of the magnetotelluric (MT) data, including a strike analysis of the MT data, modeling parameters, and model fits to the data.

\section{Text S1.}

MT data were collected along an east-west profile assuming the prominent geoelectric strike direction was generally north-south, and ease of access. Geoelectric strike is estimated using the WAL invariants (Weaver et al., 2000) and the phase tensor strike (Caldwell et al., 2004). Figure 1 displays geoelectric strike estimation for each period decade as rose plots.

In the near surface between periods of $10^{-4}-10^{-2} \mathrm{~s}$ the predominate strike direction is around $\mathrm{N} 15^{\circ}$ E. From periods $10^{-1}-10^{1} \mathrm{~s}$ the predominate strike direction rotates clockwise to approximately $\mathrm{N} 65^{\circ} \mathrm{E}$. At longer periods $\left(>10^{1} \mathrm{~s}\right)$ the strike angle rotates back to ap-proximately $\mathrm{N} 10^{\circ} \mathrm{E}$. The rotation in the strike angle at $10^{-1}-10^{1} \mathrm{~s}$ is dominated by stations in the Ivanpah Mountains (stations 07-16 in Figure 2). The set of stations between 07 to 15 all rotate towards Ivanpah Valley and dominate the strike estimation. Stations in Ivanpah Valley mainly strike $\mathrm{N} 10^{\circ} \mathrm{E}$ along the axis of the valley. This suggests the dominant strike direction is approximately $\mathrm{N} 10^{\circ} \mathrm{E}$ for the entire period range and is used for 2-D modeling. Another diagnostic tool for 2-D modeling of MT data is an estimate of the phase tensor skew angle $(\beta)$. The skew angle is the degree to which electrical currents are diverted by 3-D structures. 
A skew angle of $|\beta|>3$ is considered to be affected by three-dimensional (3-D) structures (Caldwell et al., 2004). The sign of the angle defines clockwise $(+)$ or counterclockwise $(-)$ rotation. The skew angle for periods of $10^{-1}-10^{1} \mathrm{~s}$ are above 3 indicating 3-D effects (Figure 2), likely related to the Cima Volcanics or distant sedimentary basins.

To model the MT data in 2-D, different rotation angles were tested, namely $\mathrm{N} 10^{\circ} \mathrm{E}$ and $\mathrm{N} 65^{\circ} \mathrm{E}$ $10^{-1}-10^{1}$ seconds were given larger error floors to allow the inversion to find the smoothest model without adding artifacts from 3-D structures. Ultimately, using similar error floors for all the data give similar structure in the model as with higher error floors. Therefore, similar error floors were used for the preferred model. Only the transverse magnetic (TM) mode was used to invert the data due to the TM mode is less sensitive to 3-D structures. The data and model response are represented as individual stations in Figures 3 to 20.

The Occam inversion attempts to find the smoothest model possible to fit the data. To achieve this a step approach was used. Once the data errors and strike angles were tested and finalized, an initial run of the inversion was run for 30 iterations. Plotting the RMS versus model roughness a target RMS was picked where model roughness was low, meaning a smooth model. This RMS was increased by $10 \%$ and input as the target RMS for the inversion to reach, which was set to 1.20. Once the inversion algorithm reaches the target RMS it minimizes model roughness to attain a smooth model.

The model response fits the data well with an RMS of 1.20. The model has trouble fitting station 13 and some high low periods in nearby stations. This could be caused by noise from the working mine or by being close to the highway. The subsurface resistivity structure under station 13 is 3-D according to the skew angles, which indicates that 2-D modeling has difficulty fitting the data.

\section{References}

Caldwell, T.G., Bibby, H.M., \& Brown, C. 2004. The magnetotelluric phase tensor. Geophysics Journal, v. 158, p. 457

Weaver, J.T., Agarwal, A.K., Lilley, F.E.M., 2000. Characterisation of the magnetotelluric tensor in terms of its invariants. Geophysical Journal International 141, 321-336. 

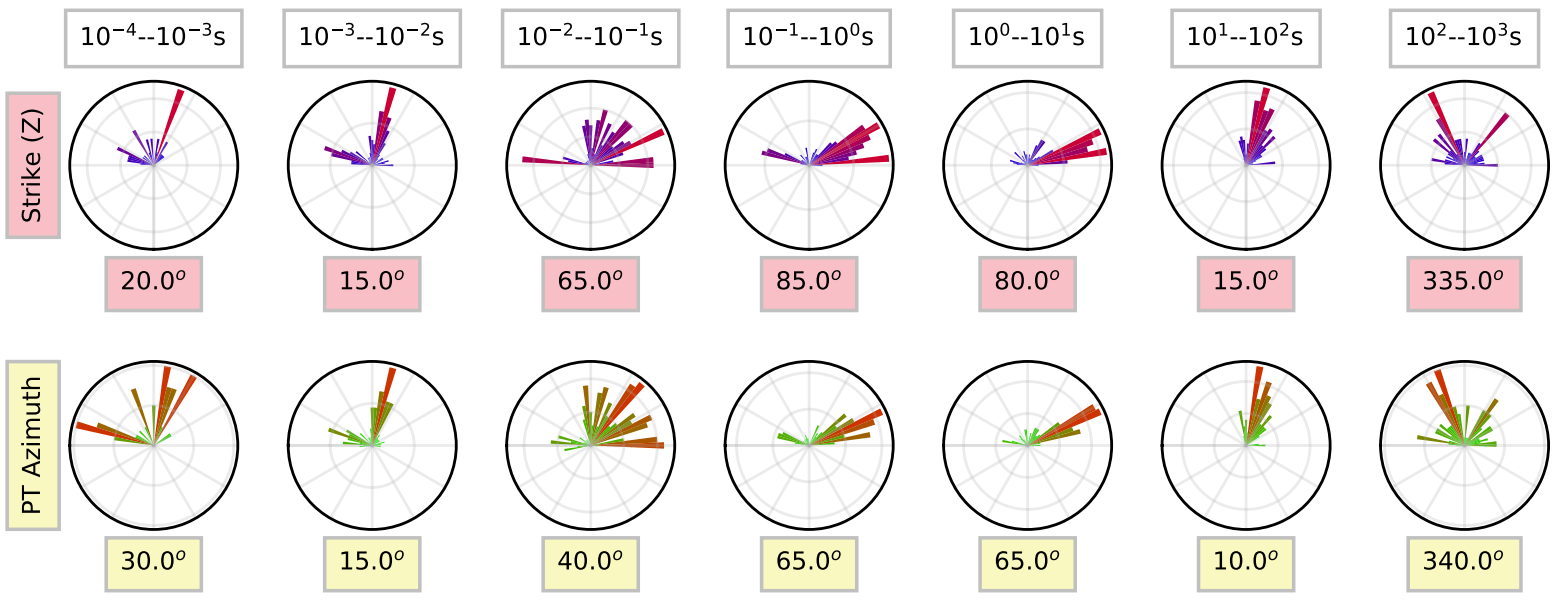

Figure 1: Strike analysis of the MT data is determined by estimating the WAL invariant strike (top row) and the phase tensor azimuth (bottom row).

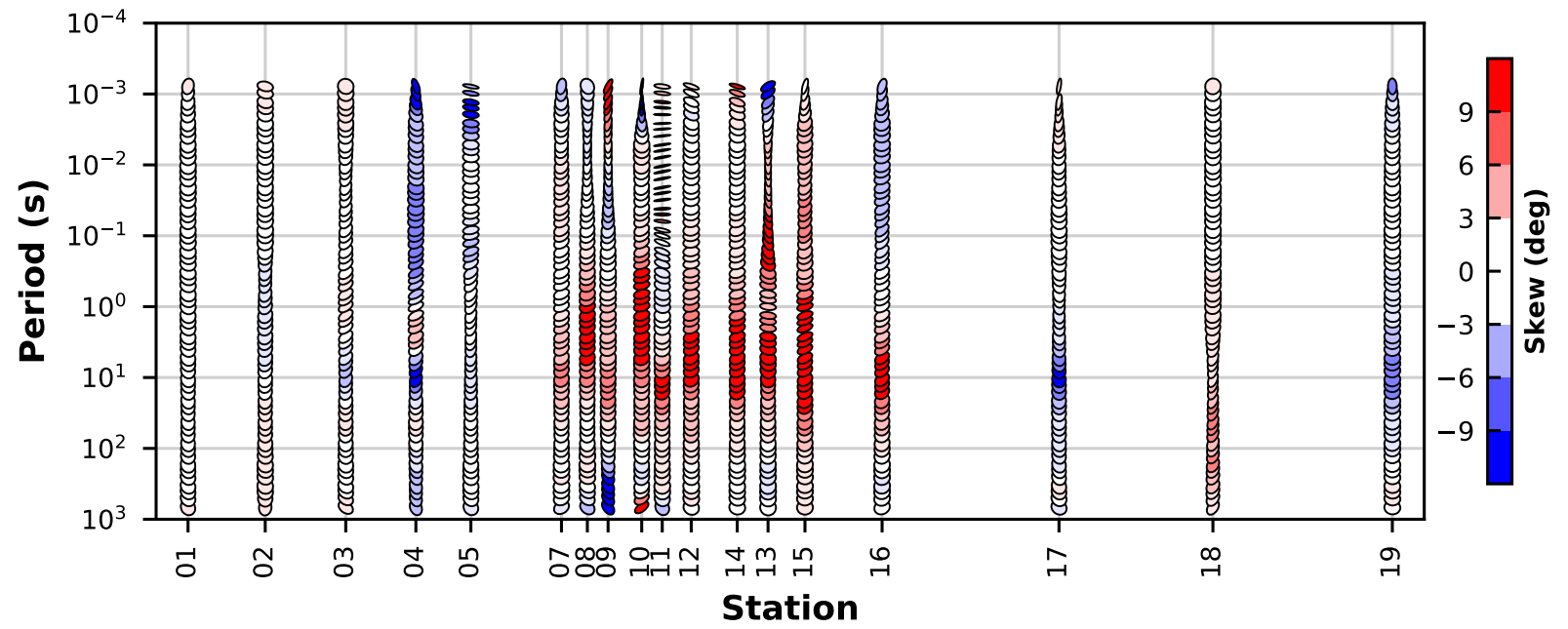

Figure 2: Pseudosection of the MT data represented as phase tensor ellipses colored by the skew angle. Each ellipse represents the map view orientation, where up is north. The direction of elongation is related to the preferred direction of electrical current flow. There-fore, circular ellipses represent 1-D resistivity structure, elongated ellipses represent 2-D or 3-D resistivity structure. Skew angles above 3 or below -3 are affected by $3-\mathrm{D}$ resistivity structure. The carbonatite deposit is located between stations 09 and 10 . 
MP01
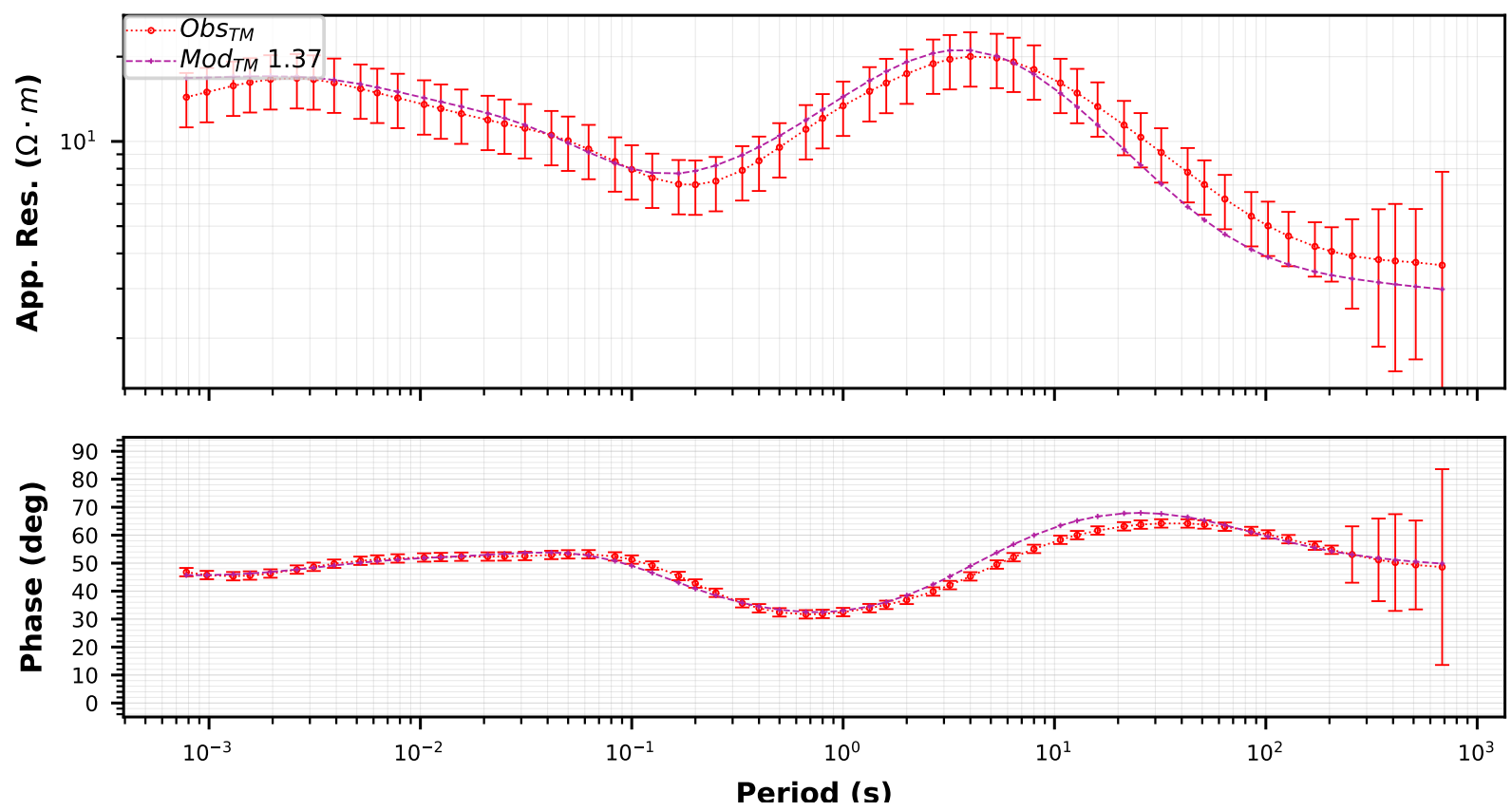

Figure 3: Data $\left(\mathrm{Obs}_{\mathrm{TM}}\right)$ and model response $\left(\mathrm{Mod}_{\mathrm{TM}}\right)$ of transverse magnetic mode $(\mathrm{TM})$. The number next to $\operatorname{Mod}_{\mathrm{TM}}$ is the RMS of the model fit to the data.
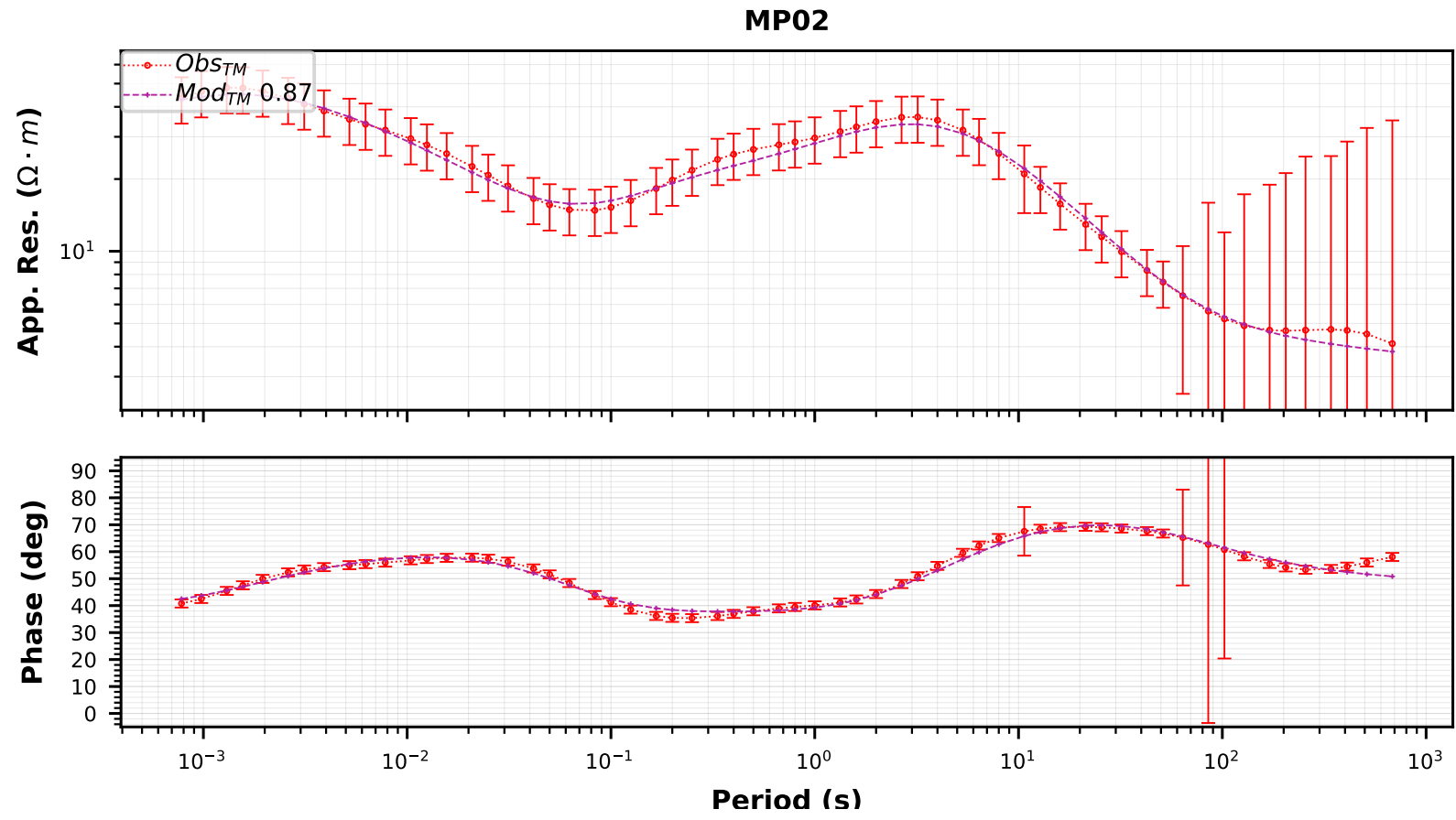

Figure 4: Data $\left(\mathrm{Obs}_{\mathrm{TM}}\right)$ and model response $\left(\mathrm{Mod}_{\mathrm{TM}}\right)$ of transverse magnetic mode $(\mathrm{TM})$. The number next to $\operatorname{Mod}_{\mathrm{TM}}$ is the RMS of the model fit to the data. 
MP03
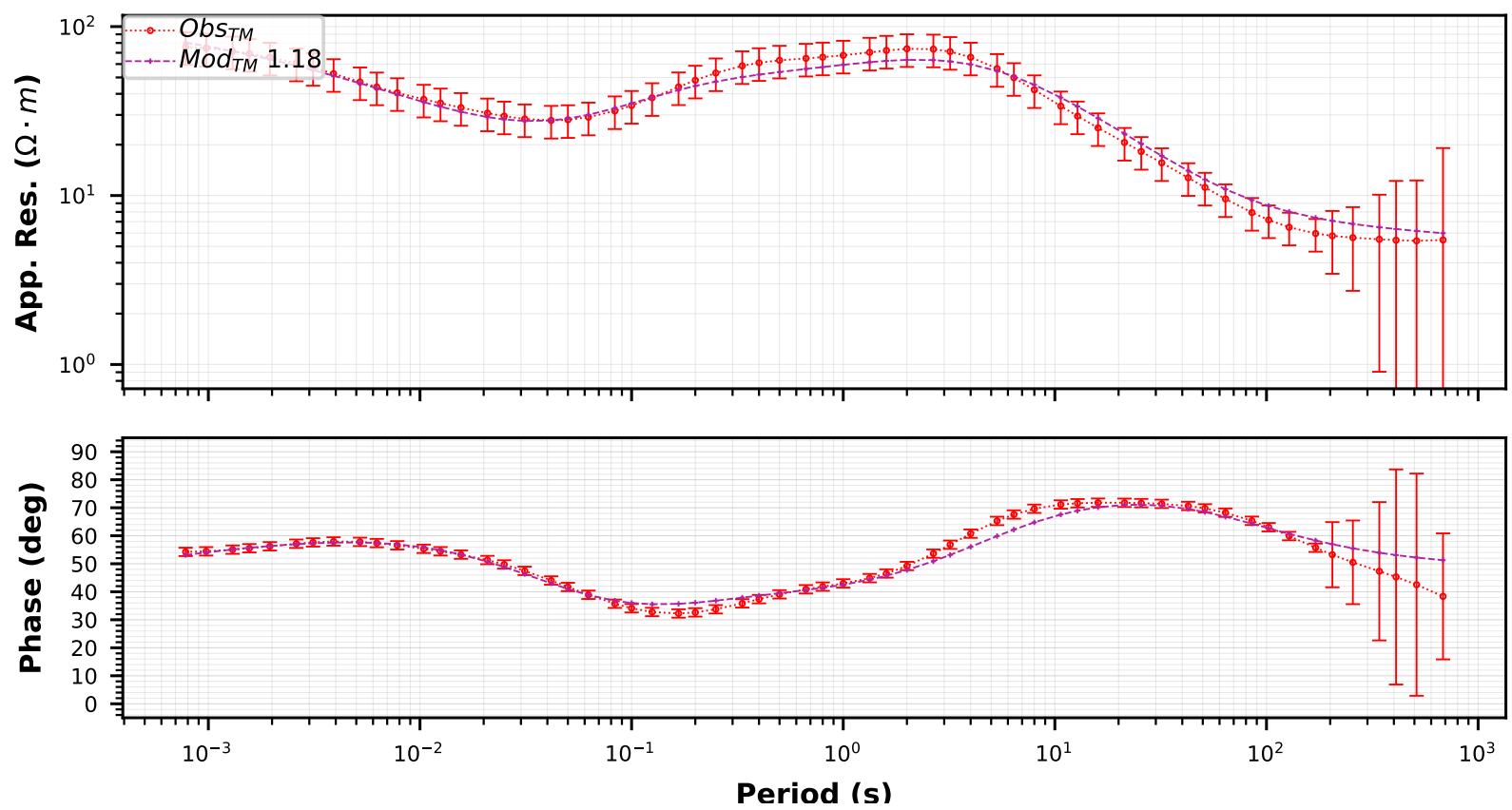

Figure 5: Data $\left(\mathrm{Obs}_{\mathrm{TM}}\right)$ and model response $\left(\mathrm{Mod}_{\mathrm{TM}}\right)$ of transverse magnetic mode $(\mathrm{TM})$. The number next to $\operatorname{Mod}_{\mathrm{TM}}$ is the RMS of the model fit to the data.
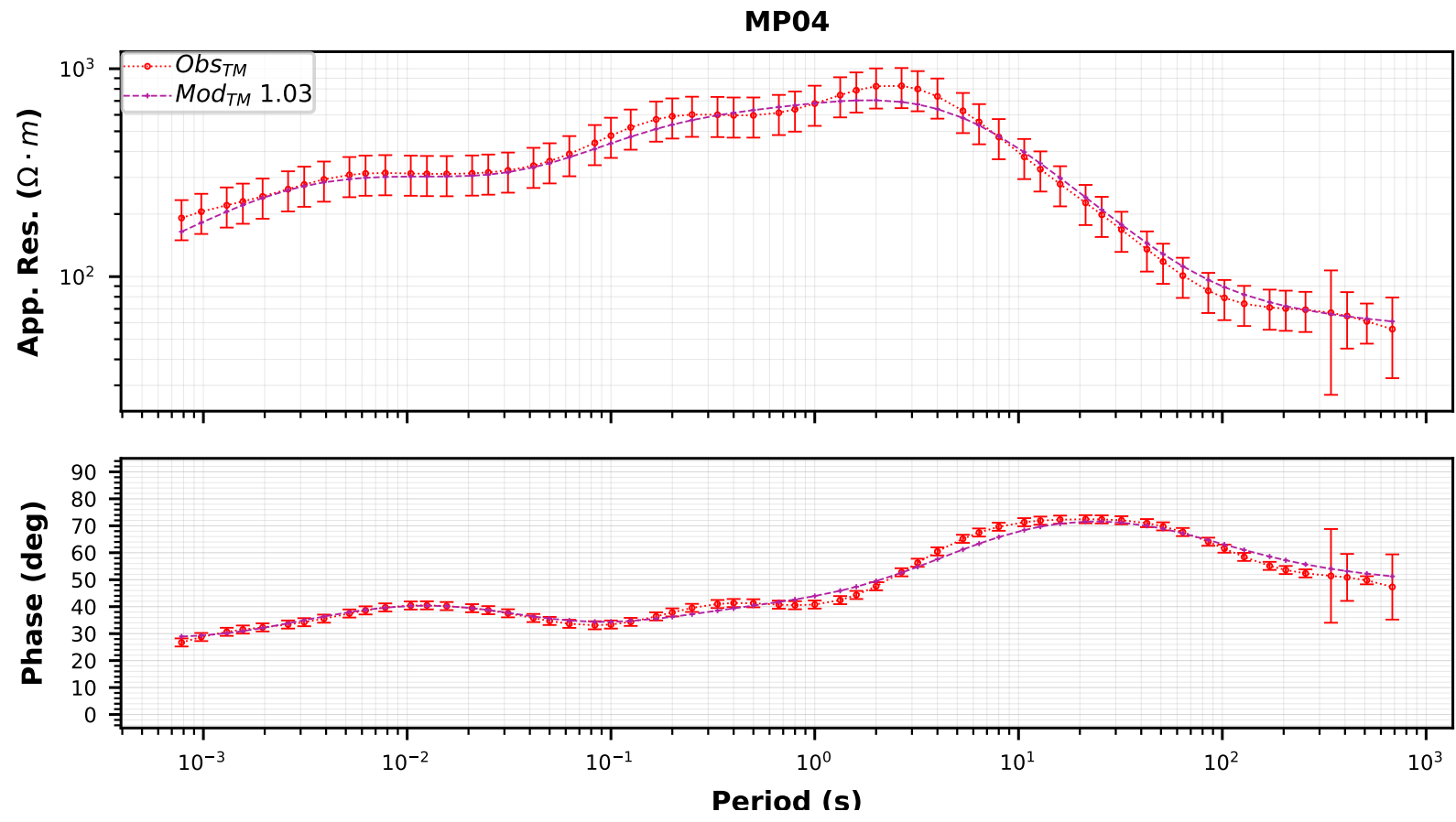

Figure 6: Data $\left(\mathrm{Obs}_{\mathrm{TM}}\right)$ and model response $\left(\mathrm{Mod}_{\mathrm{TM}}\right)$ of transverse magnetic mode $(\mathrm{TM})$. The number next to $\operatorname{Mod}_{\mathrm{TM}}$ is the RMS of the model fit to the data. 
MP05
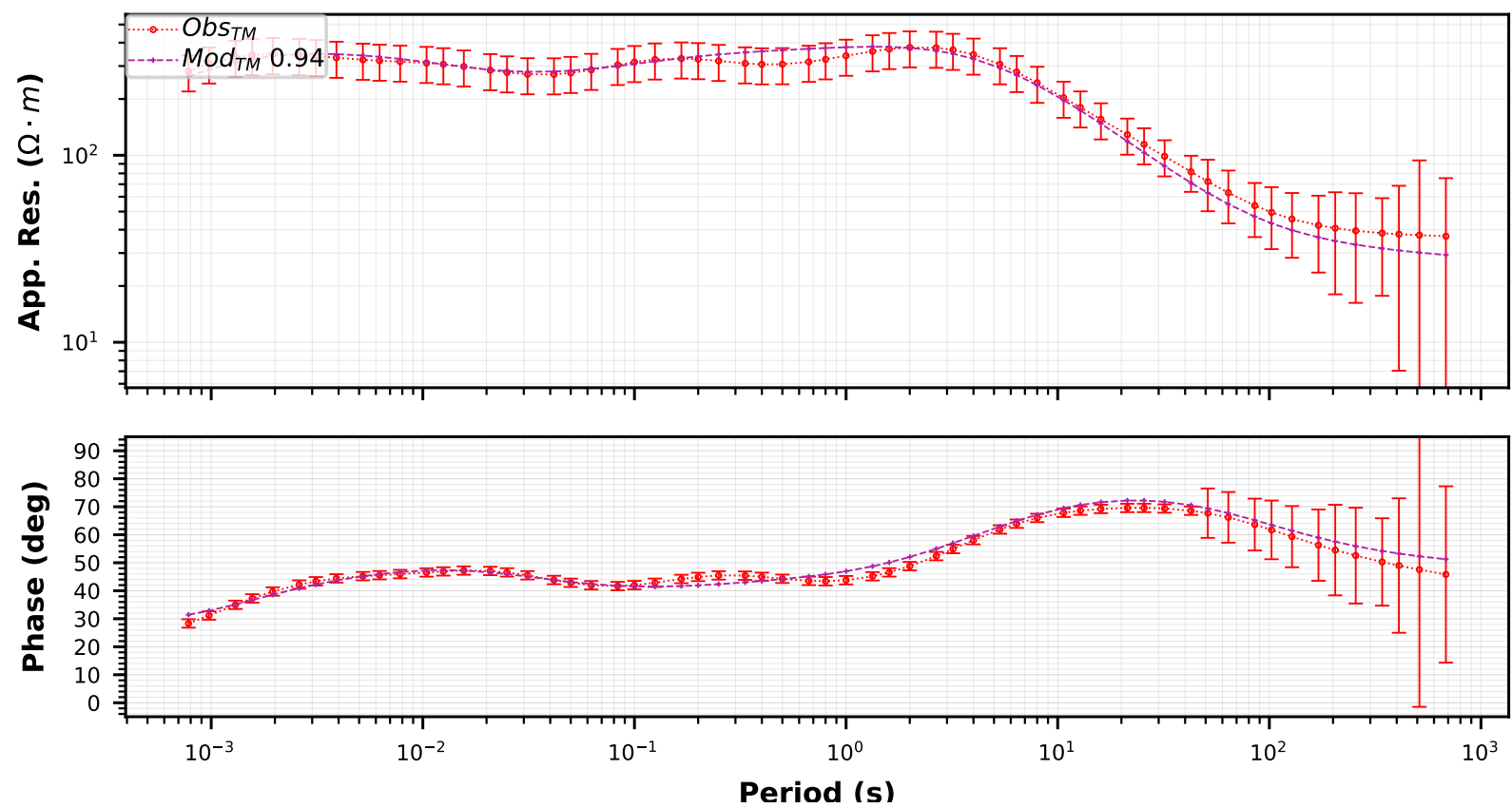

Figure 7: Data $\left(\mathrm{Obs}_{\mathrm{TM}}\right)$ and model response $\left(\mathrm{Mod}_{\mathrm{TM}}\right)$ of transverse magnetic mode $(\mathrm{TM})$. The number next to $\operatorname{Mod}_{\mathrm{TM}}$ is the RMS of the model fit to the data.
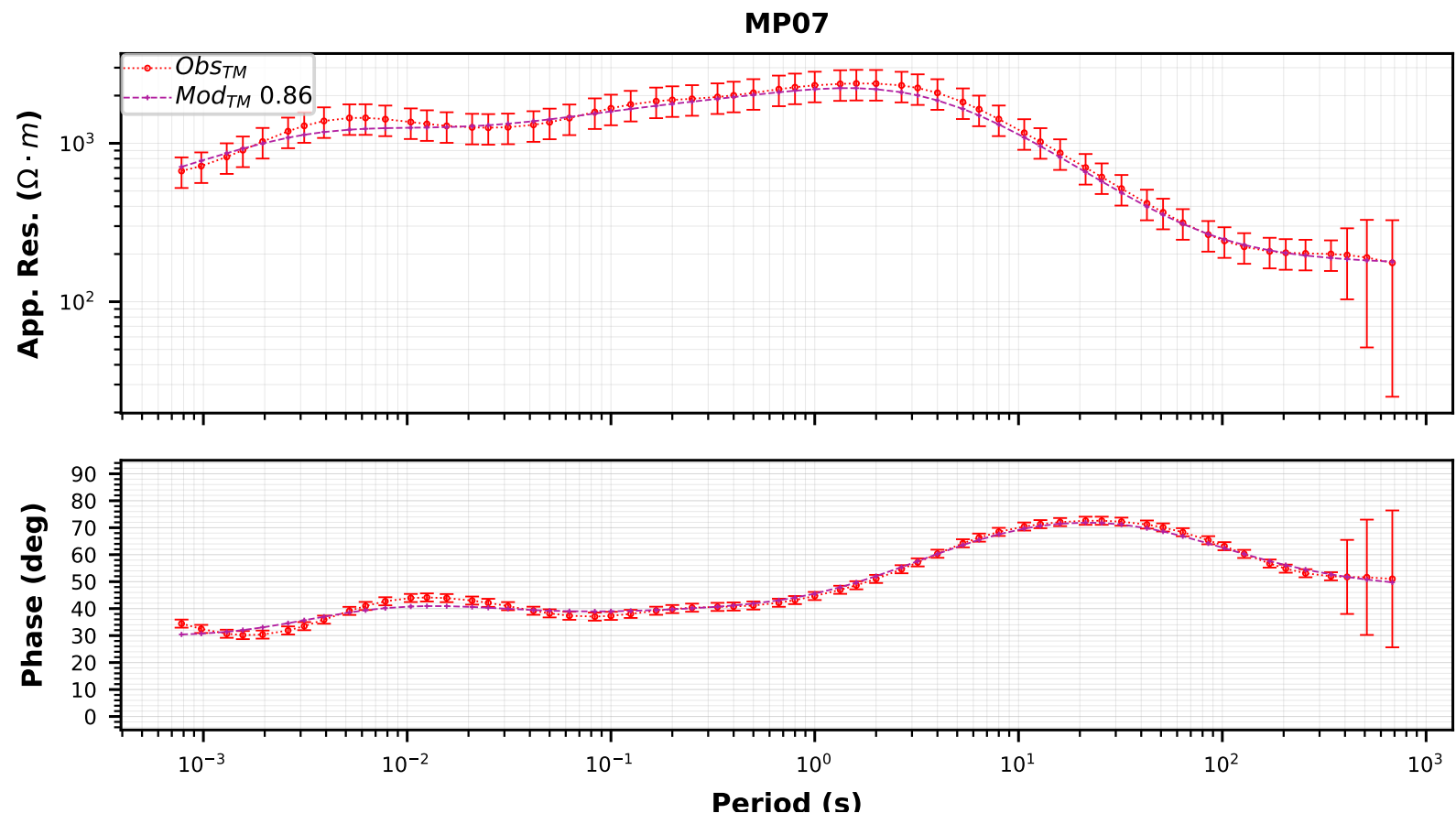

Figure 8: Data $\left(\mathrm{Obs}_{\mathrm{TM}}\right)$ and model response $\left(\mathrm{Mod}_{\mathrm{TM}}\right)$ of transverse magnetic mode $(\mathrm{TM})$. The number next to $\operatorname{Mod}_{\mathrm{TM}}$ is the RMS of the model fit to the data. 
MP08
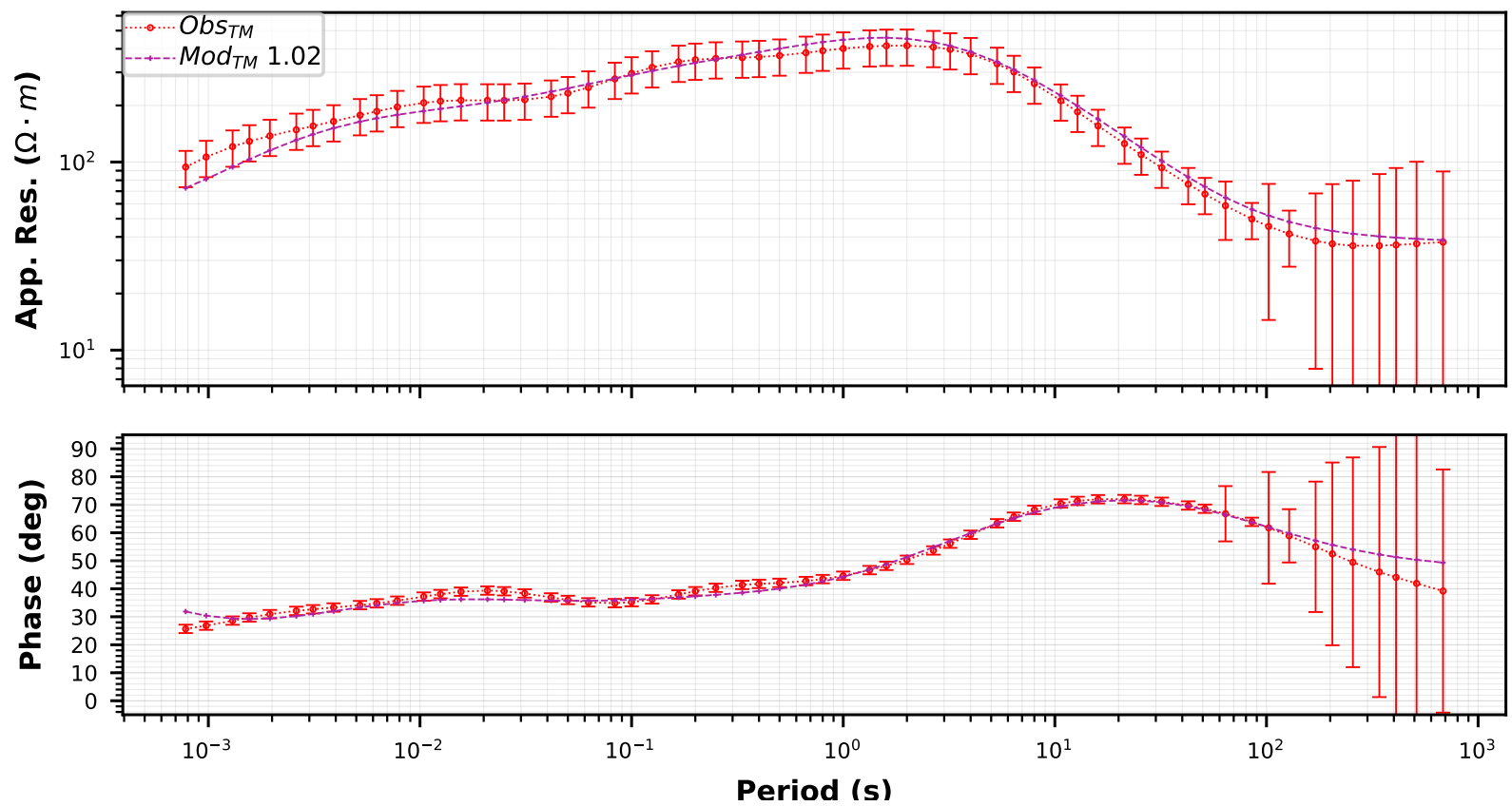

Figure 9: Data $\left(\mathrm{Obs}_{\mathrm{TM}}\right)$ and model response $\left(\mathrm{Mod}_{\mathrm{TM}}\right)$ of transverse magnetic mode $(\mathrm{TM})$. The number next to $\operatorname{Mod}_{\mathrm{TM}}$ is the RMS of the model fit to the data.
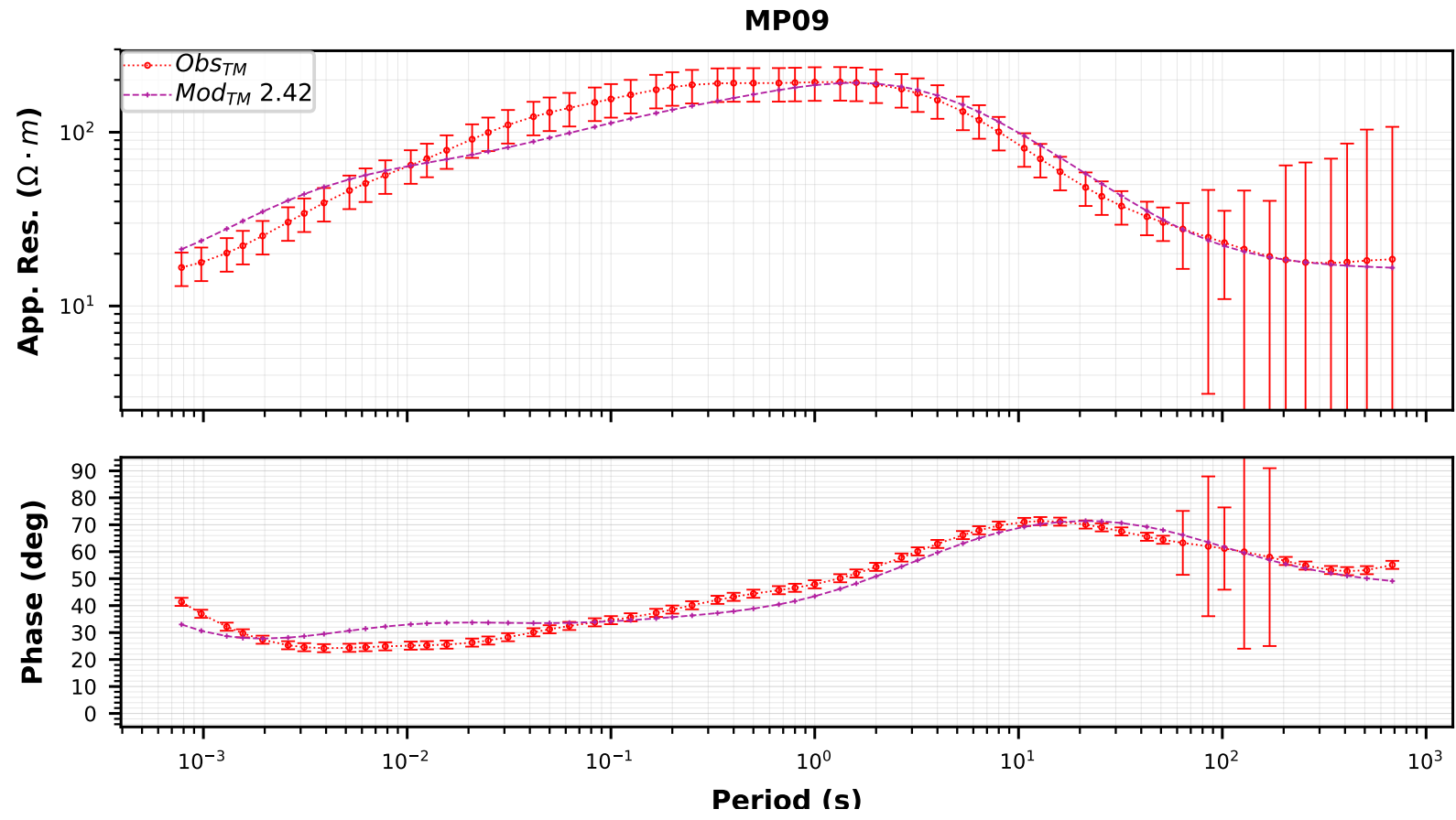

Figure 10: Data $\left(\mathrm{Obs}_{\mathrm{TM}}\right)$ and model response $\left(\mathrm{Mod}_{\mathrm{TM}}\right)$ of transverse magnetic mode $(\mathrm{TM})$. The number next to $\operatorname{Mod}_{\mathrm{TM}}$ is the RMS of the model fit to the data. 
MP10
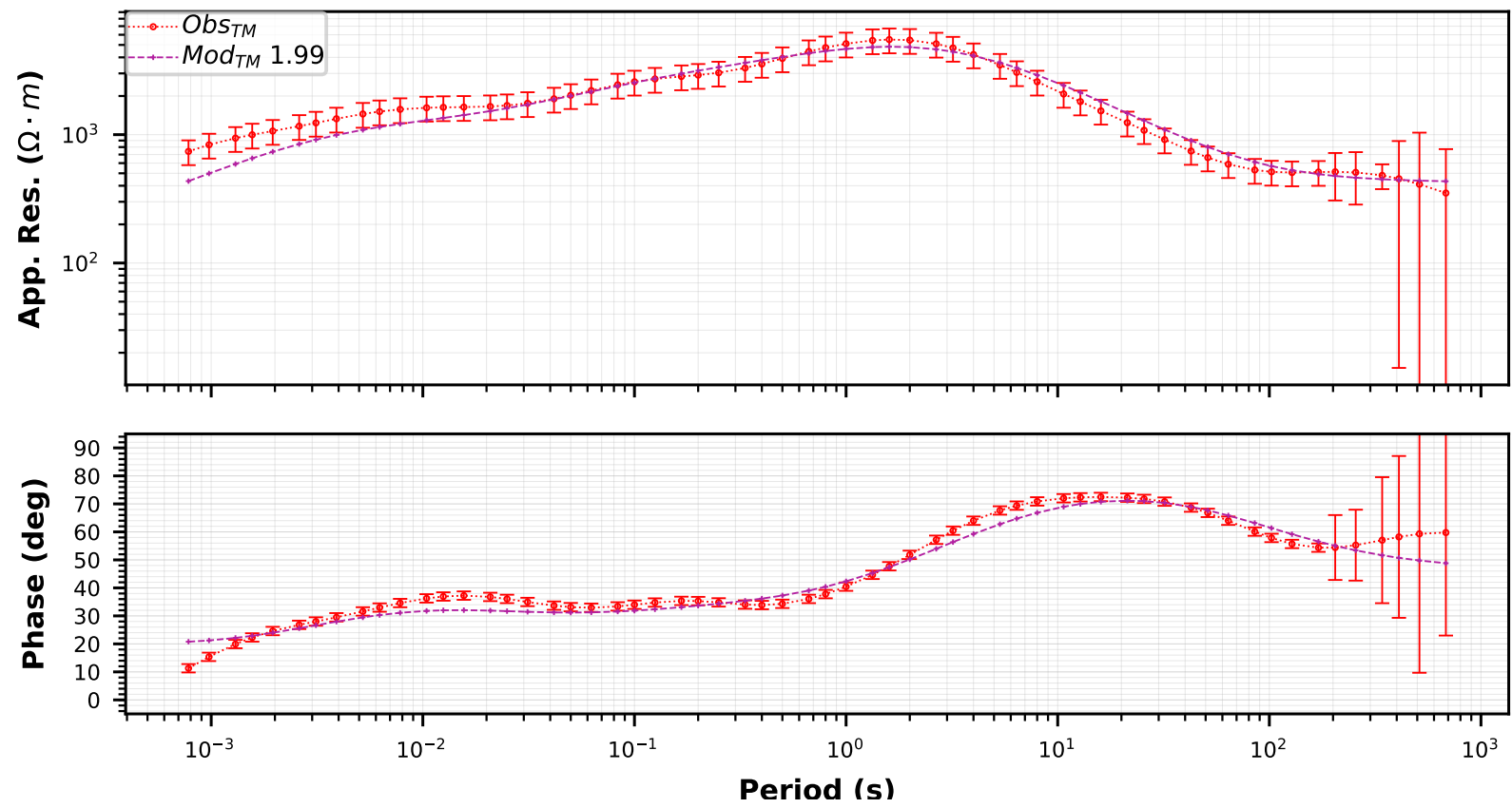

Figure 11: Data $\left(\mathrm{Obs}_{\mathrm{TM}}\right)$ and model response $\left(\mathrm{Mod}_{\mathrm{TM}}\right)$ of transverse magnetic mode (TM). The number next to $\operatorname{Mod}_{\mathrm{TM}}$ is the RMS of the model fit to the data.
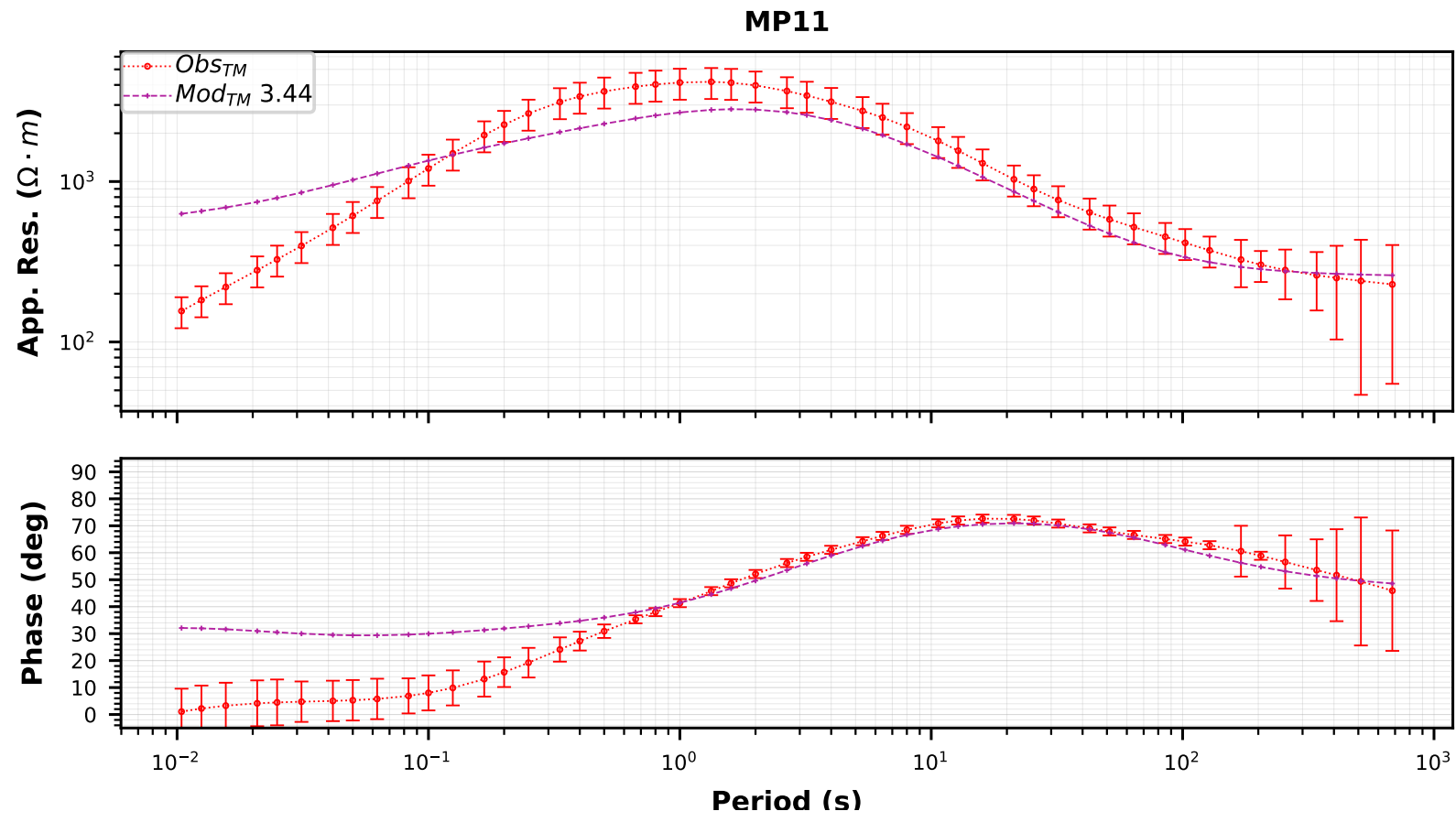

Figure 12: Data $\left(\mathrm{Obs}_{\mathrm{TM}}\right)$ and model response $\left(\mathrm{Mod}_{\mathrm{TM}}\right)$ of transverse magnetic mode $(\mathrm{TM})$. The number next to $\operatorname{Mod}_{\mathrm{TM}}$ is the RMS of the model fit to the data. 
MP12
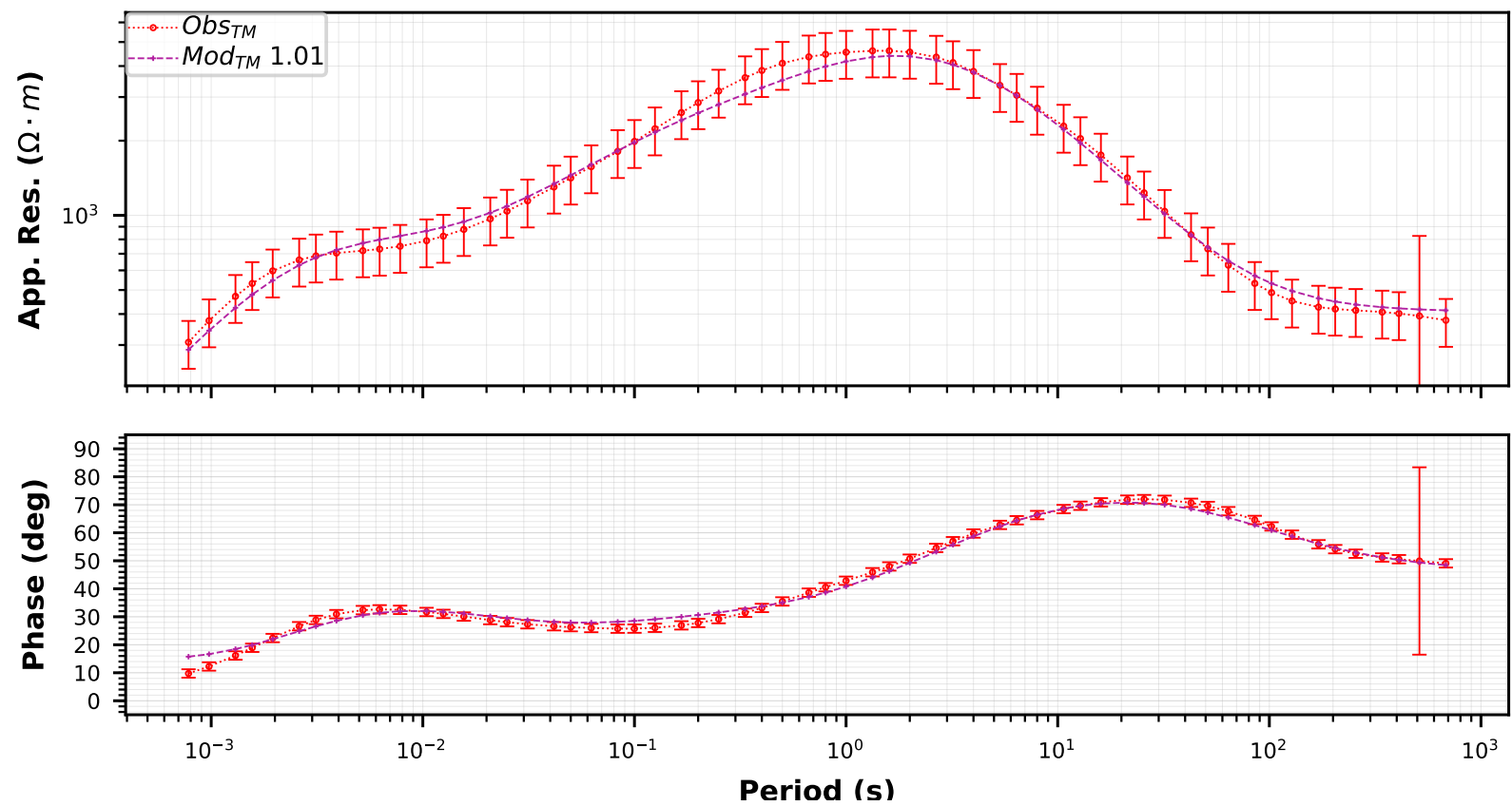

Figure 13: Data $\left(\mathrm{Obs}_{\mathrm{TM}}\right)$ and model response $\left(\mathrm{Mod}_{\mathrm{TM}}\right)$ of transverse magnetic mode (TM). The number next to $\operatorname{Mod}_{\mathrm{TM}}$ is the RMS of the model fit to the data.
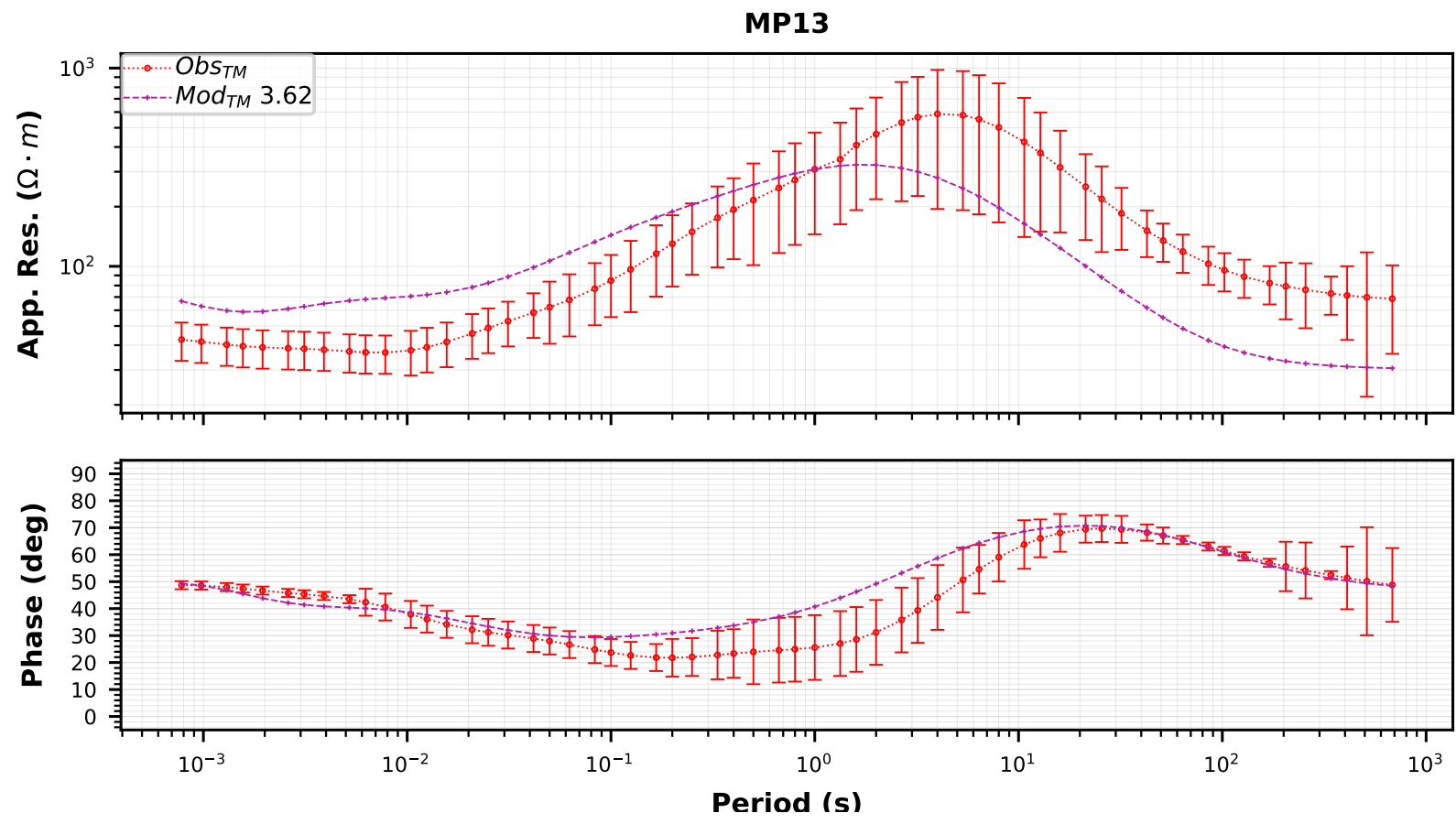

Figure 14: Data $\left(\mathrm{Obs}_{\mathrm{TM}}\right)$ and model response $\left(\mathrm{Mod}_{\mathrm{TM}}\right)$ of transverse magnetic mode $(\mathrm{TM})$. The number next to $\operatorname{Mod}_{\mathrm{TM}}$ is the RMS of the model fit to the data. 


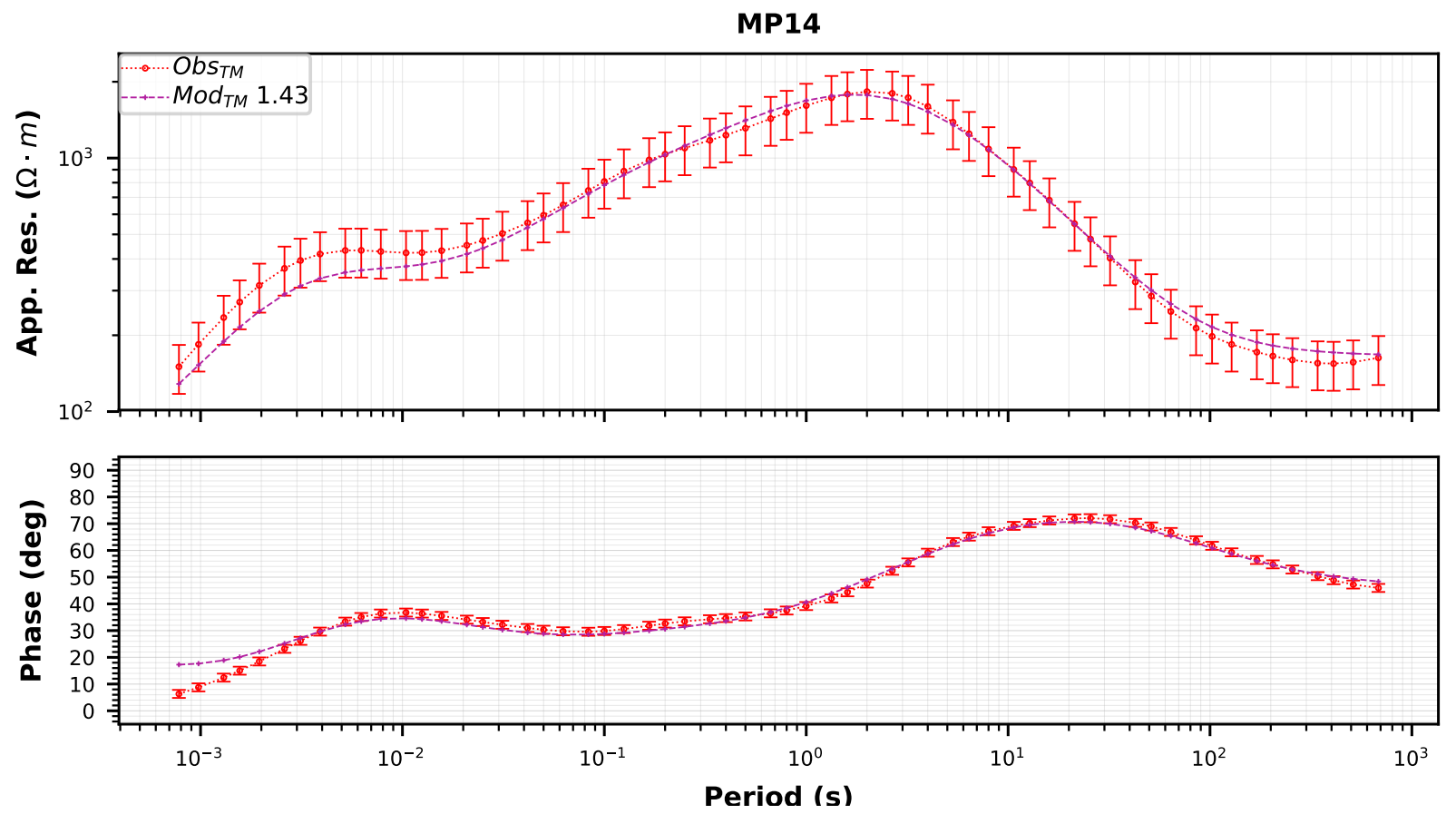

Figure 15: Data $\left(\mathrm{Obs}_{\mathrm{TM}}\right)$ and model response $\left(\mathrm{Mod}_{\mathrm{TM}}\right)$ of transverse magnetic mode (TM). The number next to $\operatorname{Mod}_{\mathrm{TM}}$ is the RMS of the model fit to the data.
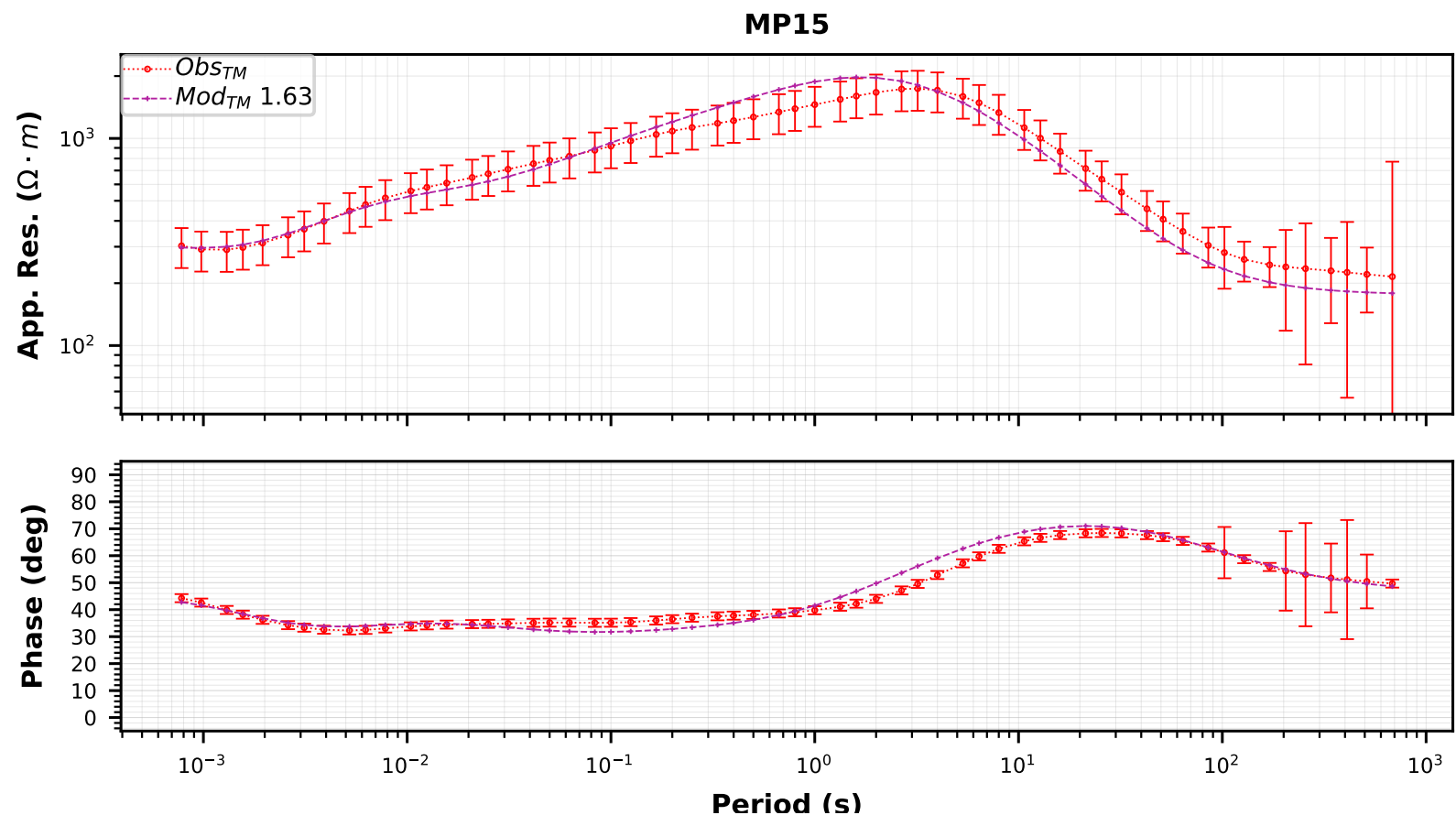

Figure 16: Data $\left(\mathrm{Obs}_{\mathrm{TM}}\right)$ and model response $\left(\mathrm{Mod}_{\mathrm{TM}}\right)$ of transverse magnetic mode $(\mathrm{TM})$. The number next to $\operatorname{Mod}_{\mathrm{TM}}$ is the RMS of the model fit to the data. 
MP16
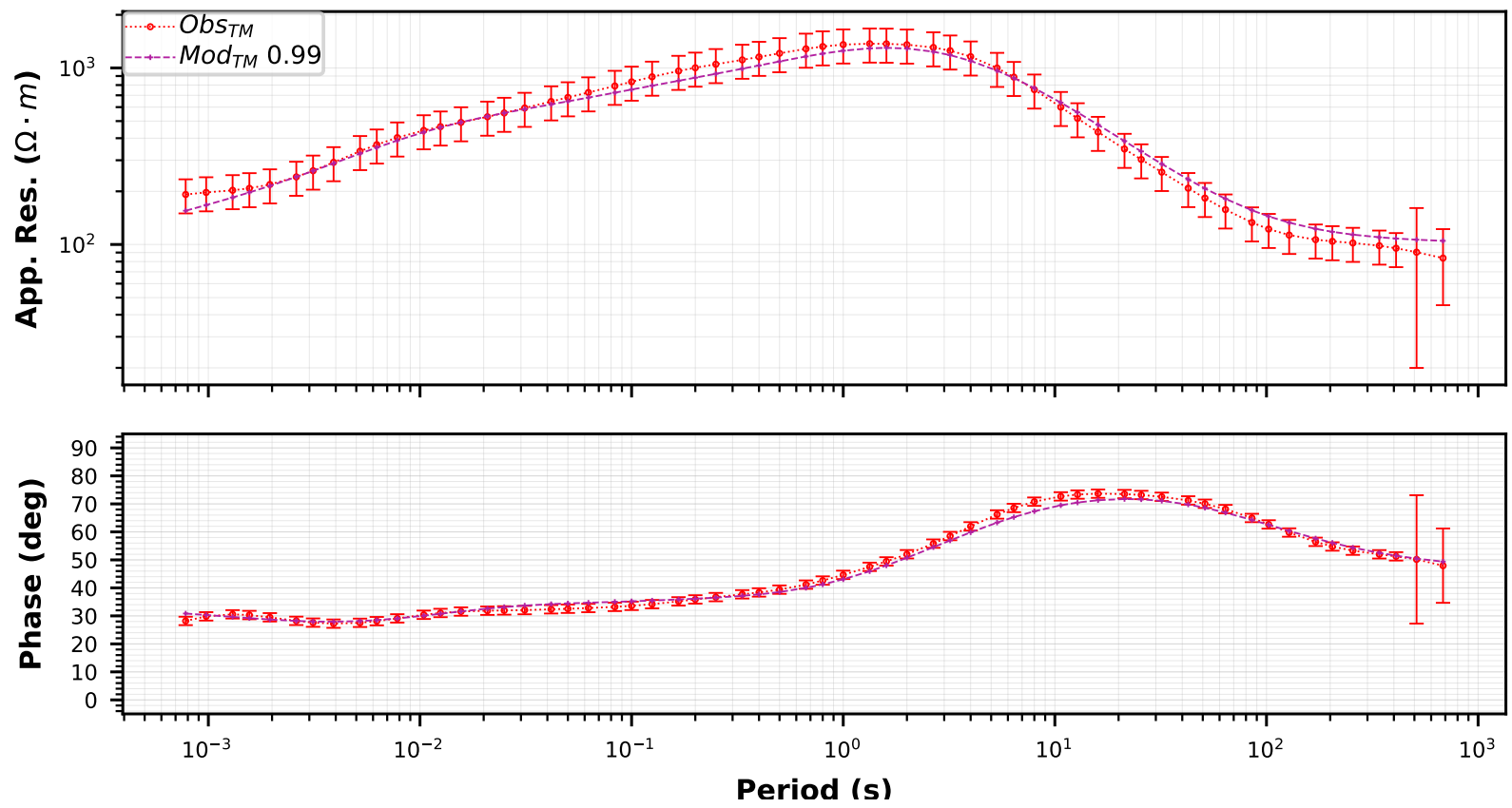

Figure 17: Data $\left(\mathrm{Obs}_{\mathrm{TM}}\right)$ and model response $\left(\mathrm{Mod}_{\mathrm{TM}}\right)$ of transverse magnetic mode (TM). The number next to $\operatorname{Mod}_{\mathrm{TM}}$ is the RMS of the model fit to the data.
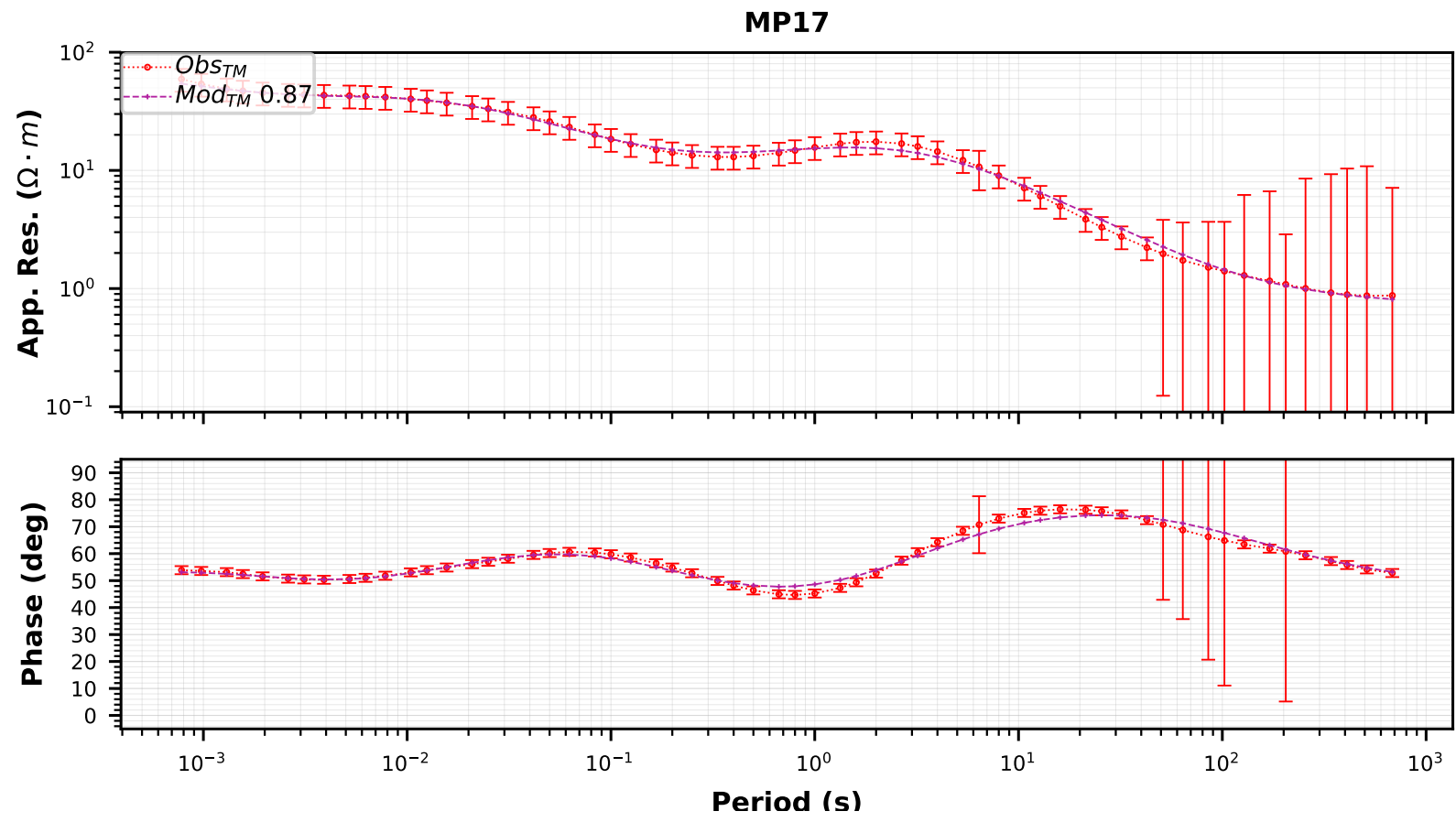

Figure 18: Data $\left(\mathrm{Obs}_{\mathrm{TM}}\right)$ and model response $\left(\mathrm{Mod}_{\mathrm{TM}}\right)$ of transverse magnetic mode $(\mathrm{TM})$. The number next to $\operatorname{Mod}_{\mathrm{TM}}$ is the RMS of the model fit to the data. 

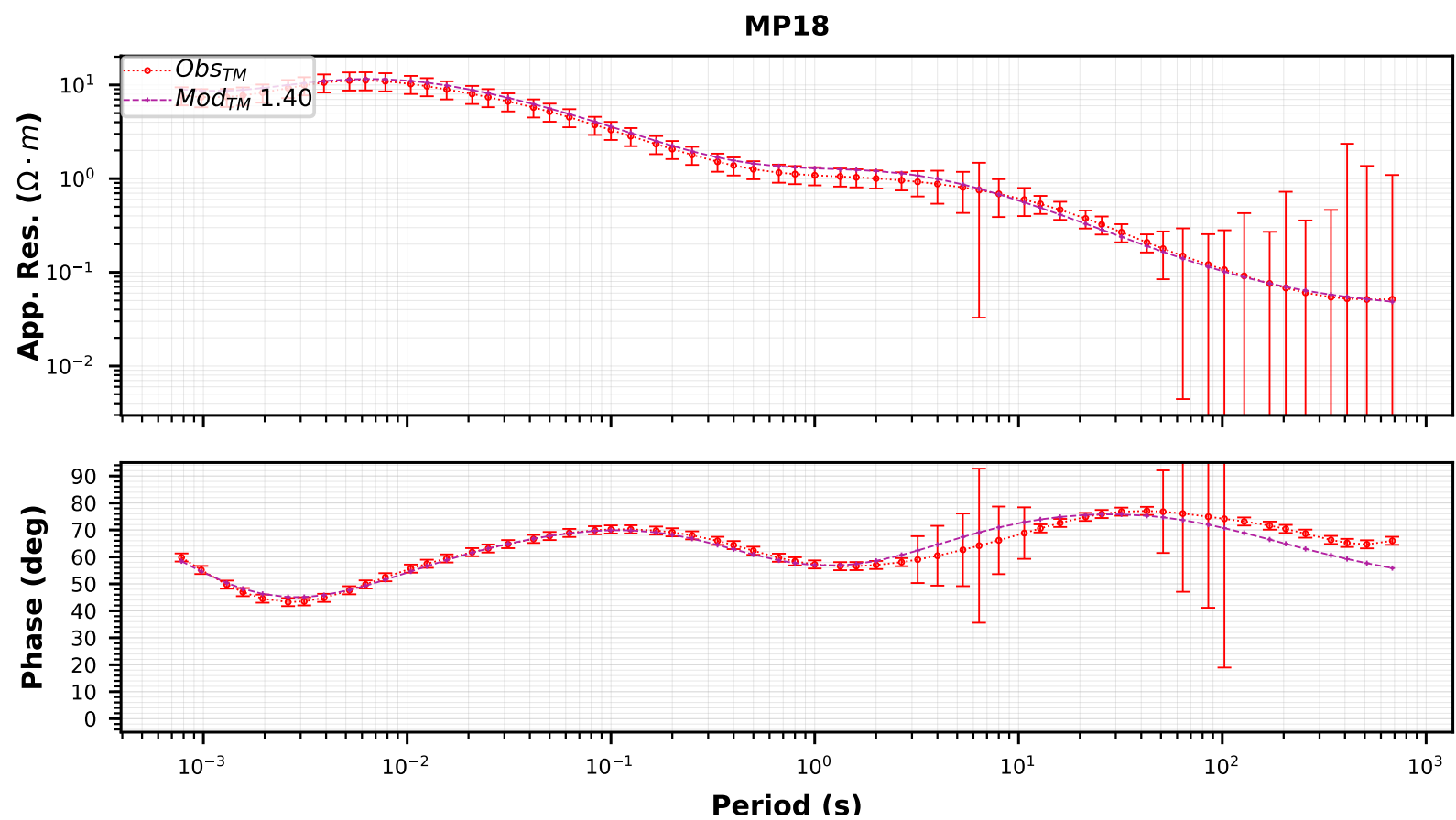

Figure 19: Data $\left(\mathrm{Obs}_{\mathrm{TM}}\right)$ and model response $\left(\mathrm{Mod}_{\mathrm{TM}}\right)$ of transverse magnetic mode (TM). The number next to $\operatorname{Mod}_{\mathrm{TM}}$ is the RMS of the model fit to the data.
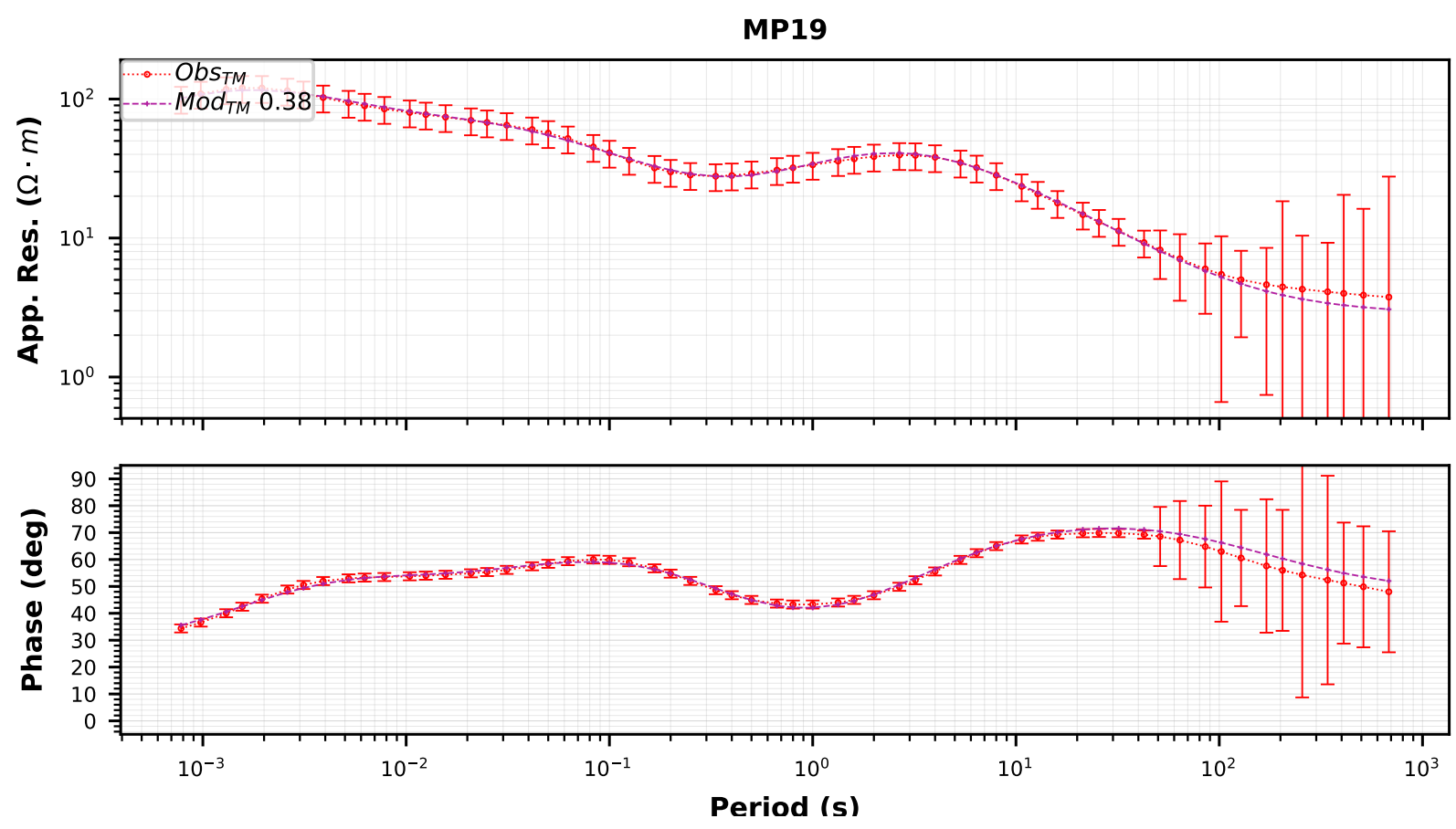

Figure 20: Data $\left(\mathrm{Obs}_{\mathrm{TM}}\right)$ and model response $\left(\mathrm{Mod}_{\mathrm{TM}}\right)$ of transverse magnetic mode (TM). The number next to $\operatorname{Mod}_{\mathrm{TM}}$ is the RMS of the model fit to the data. 